\title{
Discussion on the Communication Strategy of Mobile Phone News Client from the Perspective of New Media Communication
}

\author{
Li Lixuan \\ Faculty of Journalism and Communication, Shaoguan University, Shaoguan 512005, China
}

Keywords: new media news client strategy

\begin{abstract}
With the development of the times, the era of knowledge economy has come. In recent years, the development of intelligent mobile phone to mobile phone has become indispensable to people's life belongings in the new media development like a raging fire now, mobile phone news client has become the main means of news and consulting the people's daily access, so the media perspective, such as how to spread mobile phone news client has become the focus of the new media work, according to the this problem, we will analyze in detail, and gives relevant solutions, aims to promote the effective dissemination of new media news.

In the information age, the changes in the way of obtaining information and the changing of reading habits make mobile phone news clients develop rapidly. Mobile phone news client professional and convenient as a whole, so that people can understand whenever and wherever possible the world was changing, in this context, the traditional media have a great impact, while the new media gradually developed, mobile phone news client has gradually become the focus of the development of new media.
\end{abstract}

\section{The time significance of the communication of the mobile phone news client from the perspective of the new media communication}

With the progress of the times and the improvement of people's needs for life, people's needs have the characteristics of professionalism and convenience in the information consultation and acquisition. In today's fast-paced life, people seldom have time to browse newspapers or magazines at home and work units, which requires a fast news and information acquisition way, so that people can understand current events in time. The advent of smart phones is a revolutionary solution to this problem. The mobile news client solves this problem in a timely manner, so that news and information can be delivered to people's hands in a timely and accurate manner [1].

In addition, in the new media perspective, mobile phone news client is more convenient for the news transmission characteristics is the timeliness of news, no timeliness of news as "news", and the mobile phone news client in this aspect is very has the advantage of traditional media can not be timely for the the audience in a timely manner to push hands, therefore, the era of new media, press to continue to play an irreplaceable role, and the degree of integration of new media to deepen, it can be said that the mobile phone news client is the inevitable development of the times, this kind of high effective communication is the inevitable choice of social development[2].

From the perspective of new media, it is a new choice for people to get information through the news client of the mobile phone. In addition to newspapers and magazines in traditional media, mobile news client, as a new way of information acquisition, is not only convenient and quick, but also has low cost and high efficiency. At present, the national mobile phone use rate is gradually increased, according to statistics, the use of mobile phone users every day each time more than 2.7 hours, in addition to the use of other mobile phone APP, for the use of news client in about 0.7 hours or so, with the development of information era and the Internet, the audience can use mobile phone at any time any place to get information, but for some mainstream media attention was high, for example, people's daily, Phoenix News, xinhuanet.com and other authoritative media clients using the degree of frequency of use has exceeded its traditional media, can be seen from this point, the use of mobile phone news client has become a new way of mass reading habits and[3]. 


\section{Communication of mobile phone news clients from the perspective of new media communication}

With the development and popularization of intelligent mobile phone, mobile phone software APP has become an integral part of people's mobile phone, mobile phone news client is so, but some mobile phone news client with user experience is not sufficient, let the user experience in the use of the process is not good, first of all, is the human nature is not enough, mobile phone as a special news in the media, considering the process of commercial value, also want to pay attention to humanized design, some are forced to push advertising news client in use, do not read the advertisement can not continue to browse news, and so on, and must first login to browse through the mobile phone number of the situation; in addition, personalized settings page the design, the font size and the user did not reflect the characteristics of human nature, so that the user will get some To deal with these ads in return in low spirits, and landing restrictions, there is no interest in browsing news[4].

In addition, the setting of good video in the news is not completely humanized. Although the popularity of WIFI is expanding, but has not yet achieved full coverage of WIFI, users browse news, inevitably there will be no WIFI, the use of mobile phone traffic, and as everyone knows, pictures and video traffic is large consumption, some news client in case the user's knowledge, as long as the user clicks open the client, related pictures and videos into the buffer, so that more users browse news costs of users caused disrespect and deception, causing the user experience is not good and the unnecessary loss.

The news of the degree of polymerization is the lack of an issue at present mobile phone news client exists, some mobile phone news client just push some areas of news, or the commercial value of the news, and for users to download a mobile phone APP can only browse a part of news is not news, but this part is not necessarily a user the type of news, which leads users to download other mobile phone APP, which not only cause the waste of resources, but also reflects the mobile phone news client development is not full, highly integrated and did not realize the news resources, also lost the mobile phone news browsing convenient and fast advantages and characteristics of news.

News has the characteristics of timeliness, depth and authority. The mobile news client, as a fast communication medium of news and information, still needs to edit and push news on the basis of these three characteristics. At present, various news client market dragons and fishes jumbled together with their own characteristics, for example, some news client timeliness is very good, may have just happened, less than half an hour on the mobile phone client appears, but the depth and breadth is not enough, not to press in-depth excavation, which leads to insufficient authoritative news; secondly, some news client very authoritative news release are official views and opinions, but the lack of timeliness, things have happened in the past may have one to two days, that is reflected in the news client, which became the "old news", interested audience may already have been on the news well, this time to release, without limitation, the value and significance of the news is not big, therefore, speed, depth and breadth of not fully become One of the problems that exist in the development of mobile phone news client.

\section{The communication strategy of mobile phone news client from the perspective of new media communication}

Humanized design is a kind of satisfaction for the user to arrange, be respected and pay attention to in the process of use. The individual difference of the audience is considered in the design of the mobile phone news client. The classification of the audience group is also one of the key problems in the design. In order to meet the needs of customers as the standard, constantly upgrade the product, constantly upgrade the product, the audience's user experience will be the goal of the designers.

First of all, mobile phone news client as a special news carrier, the audience want to set the page can be achieved according to their own needs, such as reading news, according to their own preferences to set the page size and page font, background and other factors, in addition, during the 
day can choose the day and at night reading mode, can choose night mode, eye protection, which fully embodies the humanized design of news client, allowing users to feel the care and respect; in addition, the advertising push to make personalized settings, to follow the attitude of not overdo sth. a news client, open, push advertising can be accepted, but cannot read each the news you need to read the ad, which reduces the audience's user experience;

Secondly, the humanized design must consider the audience reading cost and related settings of news pictures and video, if it is in the WIFI environment, can automatically buffer and play, but in the data network, will prompt the user to play and buffer, to avoid unnecessary losses to the user;

At the same time, to consider the complexity of the audience, in the design of the news client, to make use of news type can be customized according to the needs of their own interests, but not all plates together appear, let the user can not start, so that users can set according to their own preferences, automatically filter out are not interested in the news, effective improve the quality of reading and reading accuracy, improve the efficiency of information retrieval.

Let the news be highly aggregated and improve the efficiency of reading. The high aggregation of news is not only convenient for users to read, but also the development of new media, which helps to improve the integration of new media to information.

First of all, mobile phone news client to include a variety of information, news, entertainment news, financial news and other information, so that all the audience can find their own love and interest from the content; secondly, content should be rich and colorful, relative to traditional media, new media have an advantage from the root, you can add audio, video and other content, not only to meet the user needs to read the text, but also can provide a more intuitive picture and video, to better meet the reading demands of the audience[5].

In addition, mobile phone news client can be said to be a "mobile kiosks, kiosks in either local or national news and political news, can be hired, therefore, to improve the integration of resources, let the news after the polymerization in highly mobile phone news client, is the new media dissemination, represent the general trend of development mobile phone news APP.

The news has the characteristics of timeliness and practicability, mobile phone news client can not only provide the most efficient hot news for users, but also can provide fast service for users in some city, the fast pace of social life, the focus of information in a timely grasp and understanding is very important. As the media of information and information dissemination in new media era, mobile news client should take the characteristics of news and speed up the dissemination of information and information [6].

First of all, timeliness is the life of news, the hot events reported and released in a timely manner, editing and dissemination in the first time to collect information, users can browse and comment by the client, get the latest news within 24 hours; secondly, to the depth and breadth of information can not be reported to mining. Only from the news of the surface, it will lose the nature of news, news as the hotspot information of public concern, said only surface events have lost the nature of news, to further explore in depth and breadth, with events as an opportunity to find reasons for this phenomenon and mining social fundamental factors, news to attract readers interest set people thinking at the same time, cause people to think about the hot events.

Besides, users can also use news subscription and push function to edit and customize news that they are interested in, and news client will push at the first time. For example, some people may occur for local events more interested in, as long as the client in the pre setting, as long as there is a local type of news and publishing, the client will send the first time to the user, allowing users to understand the local latest information quickly and timely can participate in the news comments and discussion, increase participation user.

As a country of free speech, people will inevitably produce their own ideas and opinions when reading news. Moreover, increasing this interaction can not only release people's emotions, but also play a positive role in the establishment of a harmonious society.

As a new carrier of information communication, mobile phone news client must ensure reading convenience, set the navigation function in the page, users can browse and select different columns according to their own preferences, but also to add a comment and message function, so that users 
can comment on the news, of course, the premise is to increase the manual review comments in the background to give the shielding function, is not conducive to the socialist construction of speech, so as to avoid unnecessary unrest, while allowing the user's opinions and suggestions have been published; in addition, but also increase the function of information storage, once the user login, reasonable to hold the information for the user, so that users can continue to browse the column at the next landing content; finally, to set up, so that users can in a short period of time to search according to the topic of interest and content To increase the "search function", and "search function" should push the news and topic of the current hot news at the same time, so that users can get to know the current hot spots in time. In order to improve the user's participation, the mobile news client can be developed, and the user will have higher loyalty and dependence on the client.

\section{Concluding remarks}

With the development of the times and the progress of science and technology, people have also changed the way of reading, to read news tend to be more convenient and low cost of news client, showed a new trend of development in the new media, mobile phone news client has gradually become the main means of access to information in people's lives, in this process, the development of mobile phone the news client as a new information transmission media, of which there are still some deficiencies and shortcomings, although its development is still in its infancy, but its future prospect is quite broad, but also the development of the times, believe in the future development of the mobile phone news client as a new information transmission way, will a wide range of promotion, occupy their own space in the market, it will become a booster of information construction in china.

\section{References}

[1] Wang J. Preliminary Discussion on the Cultural Communication of Shui Nationality in Yunnan under the Perspective of New Media[C]// International Conference on Education, Management and Computing Technology. 2014.

[2] Meredith M J. Strategic Communication and Social Media: An MBA Course from a Business Communication Perspective. [J]. Business Communication Quarterly, 2012, 75(75):89-95.

[3] Faulhaber G R. A National Broadband Plan for Our Future: A Customer-Centric Framework[J]. Social Science Electronic Publishing, 2009, 3(5):742-U795.

[4] Wang S, Han R, University N I. Discussion on the Translation of Technological News from the Perspective of Intercultural Communication[J]. Journal of State Grid Technology College, 2013.

[5] Organization W H. Training for Mid-Level Managers (MLM)[J]. Geneva World Health Organization, 2008.

[6] Faulhaber G R. A National Broadband Plan for Our Future: A Customer-Centric Framework[J]. Social Science Electronic Publishing, 2009, 3(5):742-U795.

About the authors: Li Lixuan, dongxiang county of Jiangxi province, October 10th, 1975. doctor of Management, lecturer. New media Communication, Internet Public Opinion 